PREPARED FOR THE U.S. DEPARTMENT OF ENERGY, UNDER CONTRACT DE-AC02-76CH03073

PPPL-3827

PPPL-3827

UC-70

Energetic Ion Behavior in the National Spherical Torus Experiment

by

S.S. Medley, R.E. Bell, E.D. Fredrickson, and A.L. Roquemore

June 2003

NM|

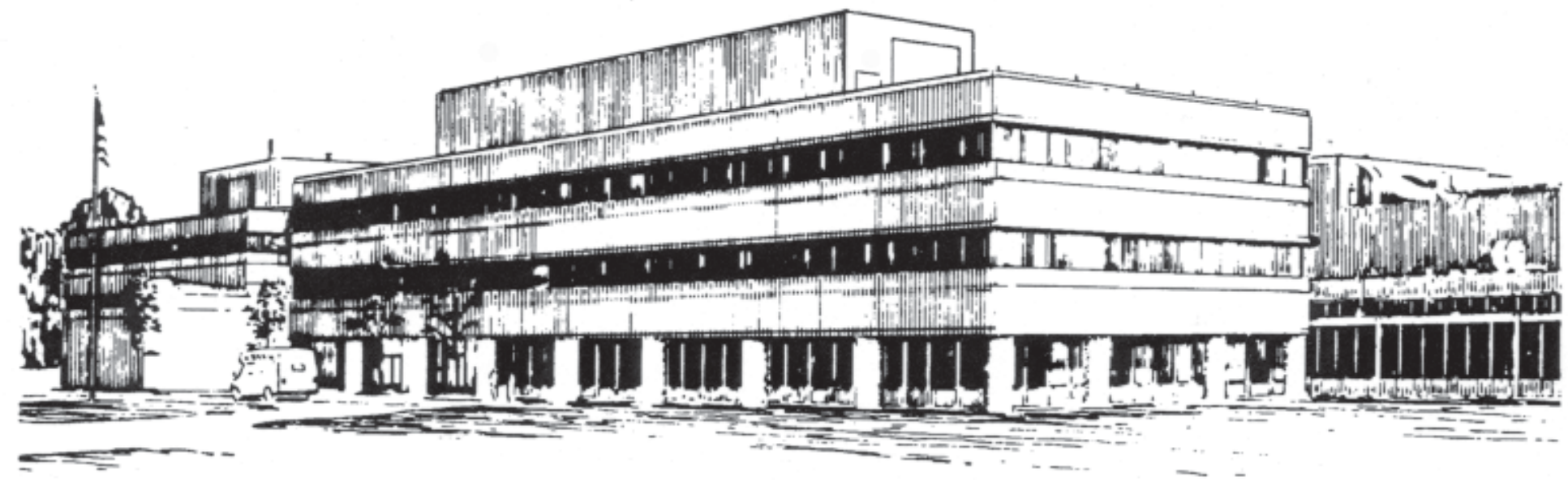

PRINCETON PLASMA PHYSICS LABORATORY PRINCETON UNIVERSITY, PRINCETON, NEW JERSEY 


\section{PPPL Reports Disclaimer}

This report was prepared as an account of work sponsored by an agency of the United States Government. Neither the United States Government nor any agency thereof, nor any of their employees, makes any warranty, express or implied, or assumes any legal liability or responsibility for the accuracy, completeness, or usefulness of any information, apparatus, product, or process disclosed, or represents that its use would not infringe privately owned rights. Reference herein to any specific commercial product, process, or service by trade name, trademark, manufacturer, or otherwise, does not necessarily constitute or imply its endorsement, recommendation, or favoring by the United States Government or any agency thereof. The views and opinions of authors expressed herein do not necessarily state or reflect those of the United States Government or any agency thereof.

\section{Availability}

This report is posted on the U.S. Department of Energy's Princeton Plasma Physics Laboratory Publications and Reports web site in Fiscal Year 2003. The home page for PPPL Reports and Publications is: http://www.pppl.gov/pub_report/

DOE and DOE Contractors can obtain copies of this report from:

U.S. Department of Energy

Office of Scientific and Technical Information

DOE Technical Information Services (DTIS)

P.O. Box 62

Oak Ridge, TN 37831

Telephone: (865) 576-8401

Fax: (865) 576-5728

Email: reports@adonis.osti.gov

This report is available to the general public from:

National Technical Information Service

U.S. Department of Commerce

5285 Port Royal Road

Springfield, VA 22161

Telephone: $1-800-553-6847$ or

(703) $605-6000$

Fax: (703) 321-8547

Internet: http://www.ntis.gov/ordering.htm 


\title{
Energetic lon Behavior in the National Spherical Torus Experiment
}

\author{
S. S. Medley, R. E. Bell, E. D. Fredrickson, and A. L. Roquemore \\ Princeton Plasma Physics Laboratory, Princeton, New Jersey, 08543, USA
}

\section{Introduction}

The National Spherical Torus Experiment (NSTX) is a low aspect ratio $(R / a \sim 1.3)$ device with auxiliary heating from neutral beam injection (NBI) and high harmonic fast wave (HHFW) heating. Typical NSTX parameters are $R_{0}=85 \mathrm{~cm}, a=67 \mathrm{~cm}, I_{p} \leq 1.5 \mathrm{MA}$, $B_{T}=0.3-0.6 \mathrm{~T}$. Three co-directed deuterium neutral beam sources have injected $P N B \leq 6.2 \mathrm{MW}$ at energies $\mathrm{E}_{\mathrm{b}} \leq 100 \mathrm{keV}$. HHFW heating has delivered up to $P_{\mathrm{RF}} \sim 6 \mathrm{MW}$ to $\mathrm{D}$ and He plasmas.

The Neutral Particle Analyzer (NPA) diagnostic on NSTX utilizes a PPPL-designed ElIB spectrometer[1] which measures the energy spectra of $\mathrm{H}^{+}$and $\mathrm{D}^{+}$ion species simultaneously with a time resolution of $\sim 1$ msec set by signal-to-noise levels. The calibrated energy range is $E=0.5-150$ $\mathrm{keV}$ and the energy resolution varies from $\square E / E=7 \%$ at low $E$ to $\square E / E=3 \%$ at high E. The detector consists of a large area microchannel plate which is provided with two rectangular, semi-continuous active area strips, one coinciding with each of the

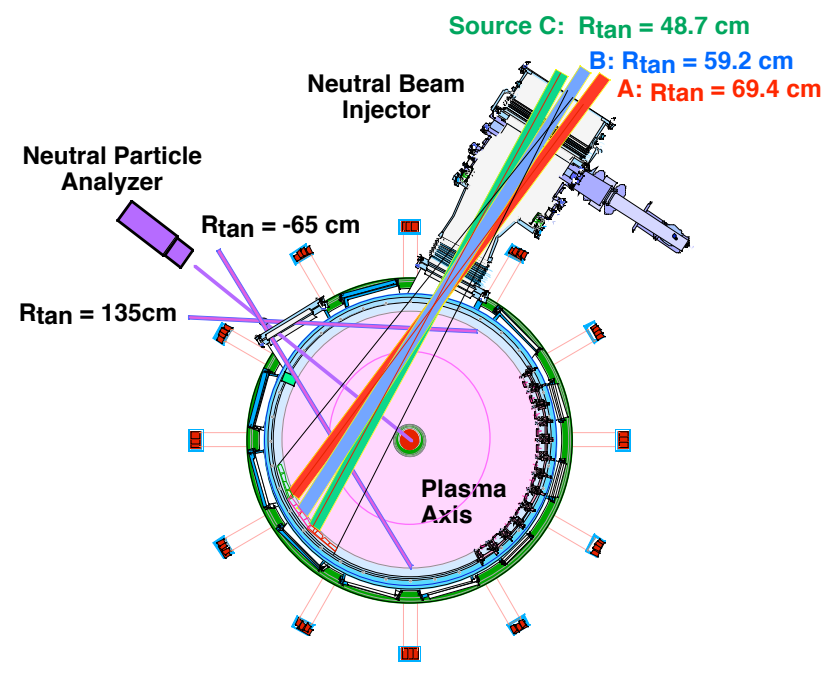

Figure 1. Neutral Particle Analyzer layout on NSTX. mass rows for detection of $\mathrm{H}^{+}$and $\mathrm{D}^{+}$and each mass row has 39 energy channels. The NPA measures Maxwellian spectra of residual $\mathrm{H}^{+}$to obtain ion temperatures, $\mathrm{T}_{\mathrm{i}}$, and $\mathrm{D}^{+}$ energetic ion spectra produced by injection of neutral beams into a D plasma. The NPA views across the co-injection paths of the three neutral beam lines on NSTX which inject at $R_{\text {tan }}$ of $70 \mathrm{~cm}$ (source A), $60 \mathrm{~cm}$ (source B) and $50 \mathrm{~cm}$ (source C) as shown in Figure 1. 
Recent implementation of horizontal scanning capability for the NPA over a sightline tangency range of $R_{T}=135 \mathrm{~cm}$ to $R_{T}=-65 \mathrm{~cm}$ has enabled measurement of the anisotropic energy distribution of the beam ions, as illustrated in Figure 2. These and other measurements[2] indicate that the slowing down $\left(\square_{b} \sim 20-30 \mathrm{msec}\right)$ and pitch angle scattering $\left(\square_{\text {scat }} \sim 30-60 \mathrm{msec}\right)$ time of energetic ions in NSTX quiescent plasmas is consistent with classical behavior.

A rich variety of energetic deuterium ion behavior resulting from magnetohydrodynamic (MHD) activity is observed in NSTX[3]. For example, onset of an $n=2$ mode leads to relatively slow decay of the energetic ion population $(E \sim 5$ -

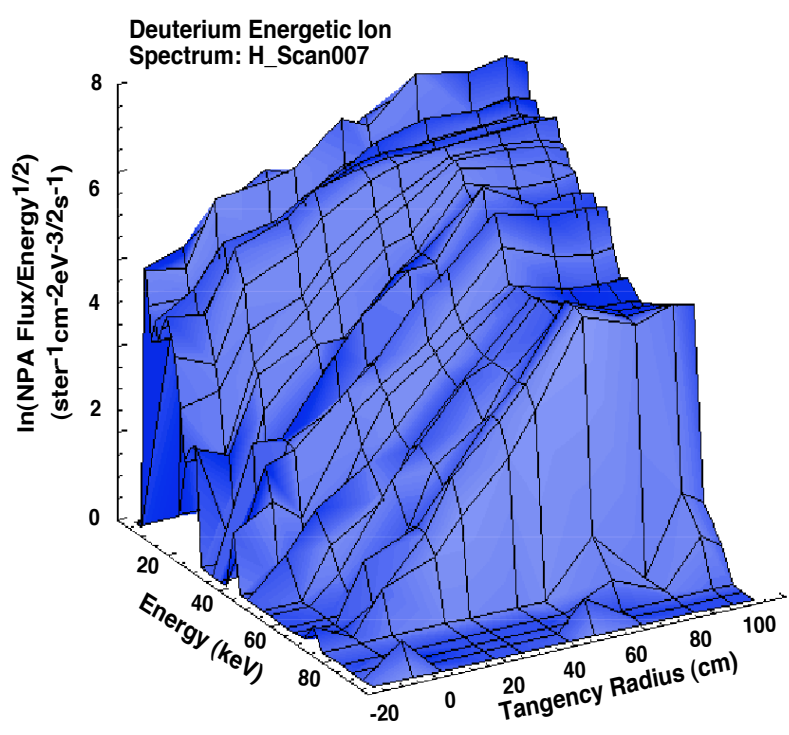
$100 \mathrm{keV}$ ) and consequently the neutron yield. The effect of reconnection events, sawteeth and Figure 2. NPA measurement of the anisotropic NB ion distribution versus energy and 'pitch angle'. bounce fishbones[4] differs from that observed for MHD modes. In this case, prompt loss of the energetic ion population occurs on a time scale of $\leq 1 \mathrm{msec}$ and a precipitous drop in the neutron yield occurs. This paper focuses the observed acceleration of MHDinduced ion loss during $\mathrm{H}$-mode operation in NSTX. TRANSP simulations of the NPA flux measurements which were performed to help understand the loss behavior will be discussed.

\section{Acceleration of MHD-induced Energetic lon Loss in H-mode Discharges}

The appearance of MHD activity can have a pronounced effect on both the 'thermal' ( $E \sim 0.5-10 \mathrm{keV})$ and 'energetic' $(E \sim 10-100 \mathrm{keV})$ ion populations in NSTX[3]. Onset of an $n=1$ or $n=2$ mode often leads to rollover and relatively slow decay of the 
energetic ion population and consequently the neutron yield. Although not discussed here, thermal ions are also lost during MHD activity which results in a collapse of the ion temperature.

An example of MHD-induced energetic ion loss during an $\mathrm{H}$-mode for NSTX discharge SN108730 is presented in Figure 3. The left panel shows the NPA spectrum of energetic NB deuterium ion flux as a function of energy and time. Following $\mathrm{H}$-mode onset at $230 \mathrm{msec}$, the spectrum exhibits a significant loss of energetic ions only for $E>E_{b} / 2$ (encircled region). Selected discharge waveforms are shown in the right panel. From the top, this is an $I_{p}=0.8 \mathrm{MA}$ discharge with sources $A$ and $B$ injecting a total of $P_{N B}$ $=4.2 \mathrm{MW}$ of power $\left(\mathrm{E}_{\mathrm{b}}=90 \mathrm{keV}\right)$. At the onset of the $\mathrm{H}$-mode marked by the dashed line

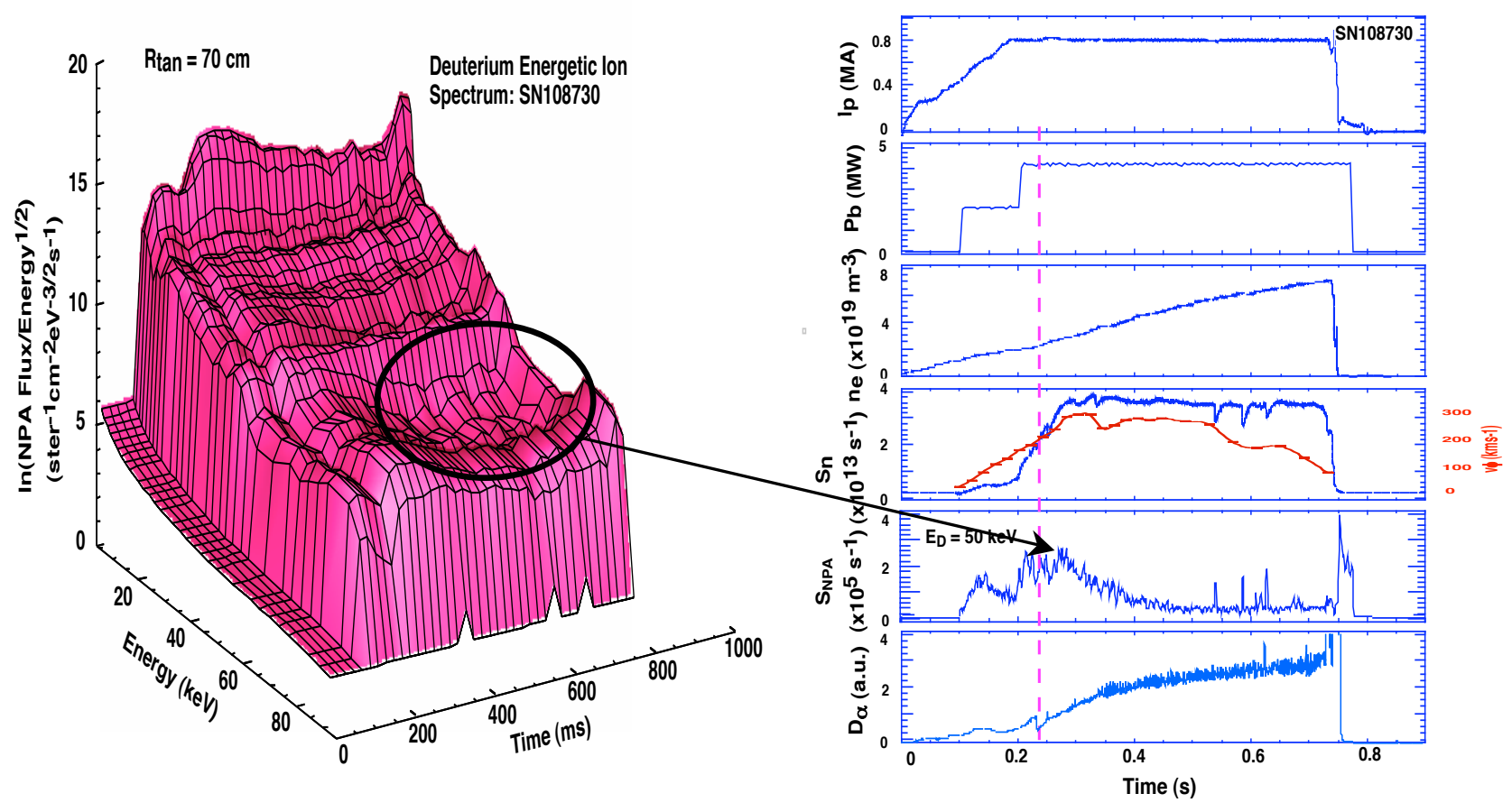

Figure 3. Following onset of the H-mode at $230 \mathrm{msec}$, the NPA spectrum (left panel) shows significant loss of energetic ions only for $E>E_{b} / 2$ (encircled region).

passing through the drop in the $D_{\square}$ signal in the bottom panel, little change is seen in the evolution of the neutron yield, $S_{n}$, the toroidal rotation velocity from the CHERS diagnostic, $\mathrm{V} \square$, or the NPA signal, $\mathrm{S}_{\mathrm{NPA}}$, shown here for $50 \mathrm{keV}$ deuterium ions just above the beam half energy $E_{b} / 2=45 \mathrm{keV}$. Shortly afterwards around $280 \mathrm{msec}$, however, the neutron 
yield and toroidal rotation velocity clamp concurrent with onset of decay in the NPA signal. An understanding of this behavior can be gained from the measurements in Figure 4.

In Figure 4, the left panel shows Multi Point Thomson Scattering (MPTS) measurements of the electron density profiles around the time of $\mathrm{H}$-mode onset (upper panel) and evolution of the electron temperature and line integral density overlaid with waveforms for plasma current and beam power as well as $D_{\square}$ and Mirnov coil signals
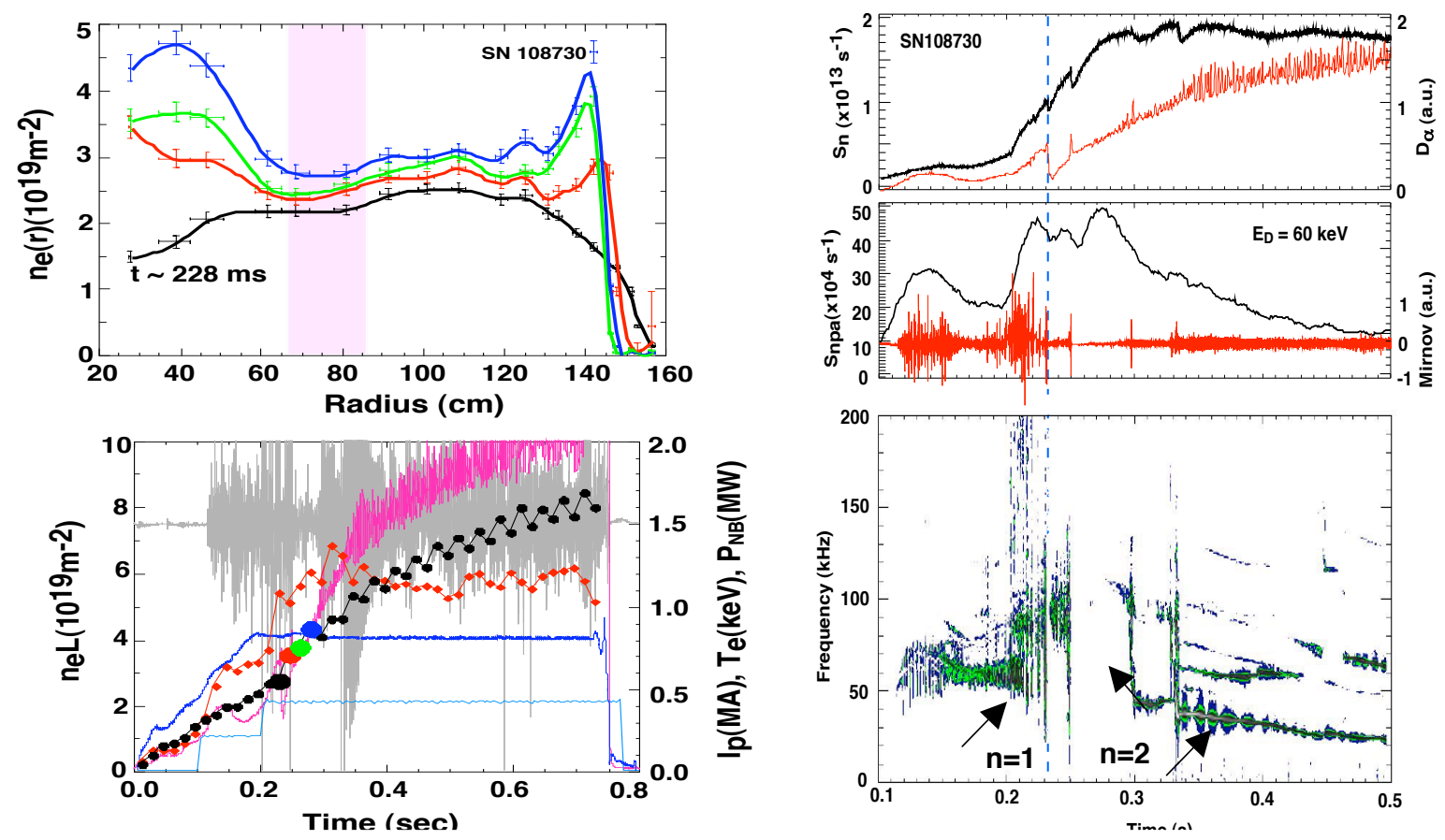

Figure 4. MPTS electron density and temperature measurements (left panel) and MHD activity (right panel)

(lower panel). The electron density profiles correspond to times flagged by color-coded solid circles on the trace for the line integral density. In the electron density profile plot, the shaded region denotes the approximate radial location of the source on the NPA signal. TRANSP simulation shows that the NPA charge exchange signal arises primarily in the region where the NPA sightline and NB injection axes intersect. This is because the density of beam primary and halo neutrals in this region exceed the passive wall neutral density by at least an order of magnitude. From the top, the right panel shows an overlay of the neutron and $D_{\square}$ signals, the deuterium NPA signal for $E_{D}=60 \mathrm{keV}$ overlaid with a typical Mirnov trace and finally the Mirnov spectrogram identifying the MHD mode activity. 
$\mathrm{H}$-mode onset at $230 \mathrm{msec}$ is marked by the dashed line. Although $\mathrm{n}=1$ activity prior to $\mathrm{H}$-mode onset arguably affects the NPA signal evolution, this period is complicated by NB turn on events and will not be examined further. In the first $\sim 200$ msec of the $\mathrm{H}$-mode, the NPA signal, $S_{\mathrm{NPA}}$, appears to be flattened by $\mathrm{n}=2$ activity which vanishes to give a quiescent phase where $S_{\mathrm{NPA}}$ increases moderately. At $\sim 280 \mathrm{msec}$, strong $n=2$ activity recurs with mode amplitude $\square \mathrm{B} \sim 0.5$ Gauss and simultaneously $\mathrm{S}_{\mathrm{NPA}}$ begins to decay and the neutron yield clamps. In the time interval from $280-400$ msec, $S_{\mathrm{NPA}}$ droops by $75 \%$. As seen in Figure 3, depletion of energetic ions with $E>E_{b} / 2$ 'saturates' and persists until termination $\mathrm{H}$-mode termination by an IRE event.
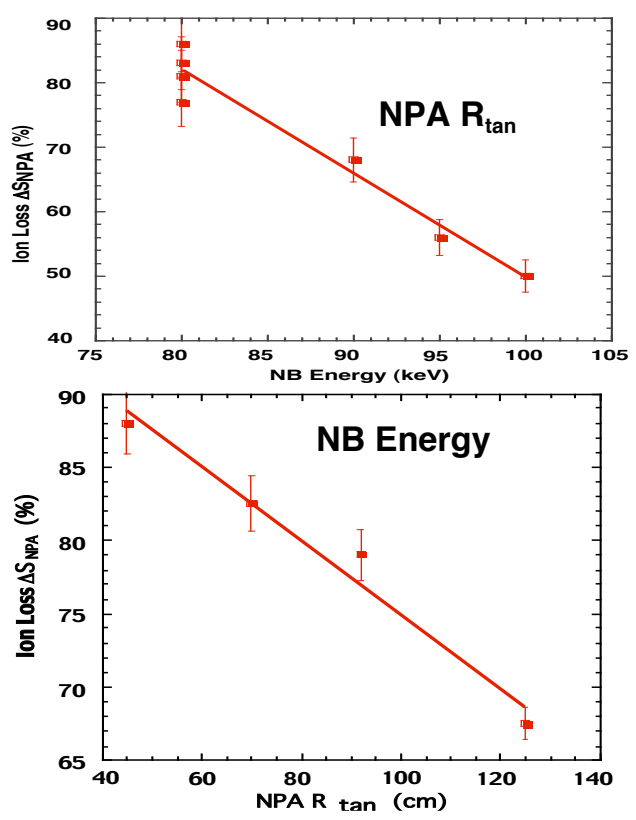

Figure 5. Scaling of ion loss with NPA tangency radius (top panel) and $N B$ injection energy (bottom).
The magnitude of the energetic ion loss (decrease of $S_{N P A}$ in the region $E>E_{b} / 2$ ) was observed to decrease with increasing tangency radius, $R_{\text {tan }}$, of the NPA sightline and with increasing NB injection energy, $E_{b}$, as illustrated in Figure 5 . In addition, the loss decreases with increasing toroidal field but a sparse data set exists since the available range was only $B_{T}=4.4-5.3 \mathrm{kG}$. Decreasing ion loss with increasing $R_{\tan }$, $E_{b}$, and $B_{T}$ can be understood by noting that increasing values these parameters act to reduce either the viewed or the generated fraction of trapped ions, this being the population affected by MHD-induced loss.

The TRANSP code is capable of simulating the NPA flux measurements including horizontal and vertical scanning of the sightline. In Figure 6 it can be seen that prior to $\mathrm{H}$ mode onset (upper spectra) reasonable agreement exists between measurement and simulation at all energies. The observed MHD-induced ion loss during the H-mode (shaded region in the lower spectra) is not reproduced by TRANSP, of course, since the code contains no model for this process but otherwise the two spectra also agree reasonably. From this one may infer that plasma opacity effects due broad electron density profiles characteristic of $\mathrm{H}$-modes is not impairing beam deposition (e g. by 

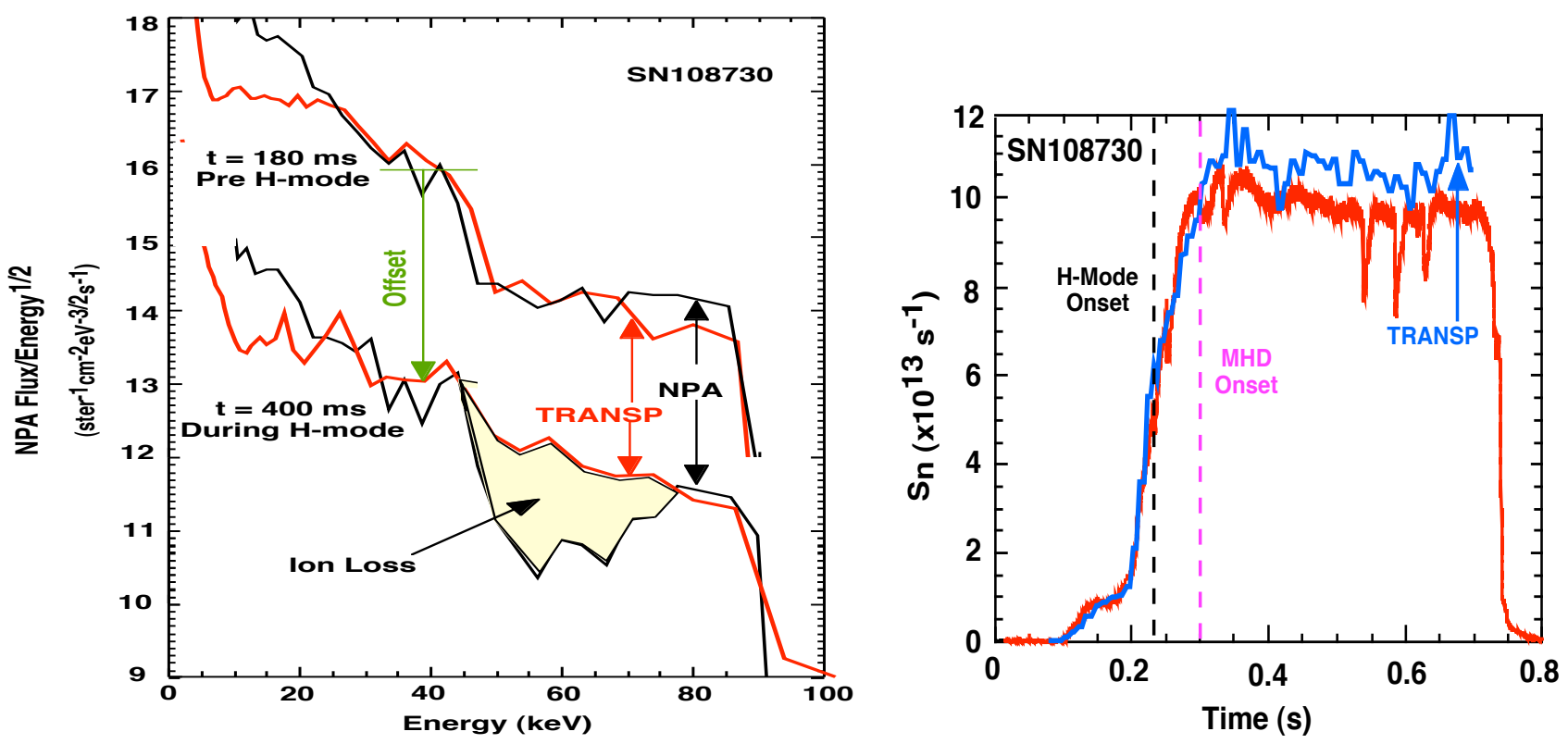

Figure 6. The TRANSP code is capable of simulating the NPA flux measurements. The measured and simulated energetic ion spectra are compared for times $t=180 \mathrm{msec}$ preceding the $\mathrm{H}$-mode and $t=400 \mathrm{msec}$ during the $\mathrm{H}$ mode(left panel). The spectra are normalized once at $30 \mathrm{keV}$ for the pre $\mathrm{H}$-mode case. Note that for clarity an artificial offset has been applied to the "during H-mode" spectra.

depositing beam ions on prompt loss orbits) nor causing the observed ion loss. As shown in the right panel, TRANSP slightly overestimates the neutron yield following MHD onset during the $\mathrm{H}$-mode phase.

\section{Discussion}

TRANSP modeling also suggests a possible mechanism causing the enhancement of MHD-induced ion loss observed during $\mathrm{H}$-mode operation as illustrated in Figure 7. Shown are TRANSP outputs for $\mathrm{t}=220 \mathrm{msec}$ prior to the $\mathrm{H}$-mode and $\mathrm{t}=280 \mathrm{msec}$ during the $\mathrm{H}$-mode corresponding to onset of the $\mathrm{S}_{\mathrm{NPA}}$ signal decay (see Figure 4). Profiles are given for the safety factor (top), deposition of the full energy beam neutrals (center) and trapped banana fraction of full energy beam ions (bottom). Following the transition to $\mathrm{H}$-mode, the q-profile evolves introducing a $\mathrm{q}=2$ surface in the region of $\mathrm{r} / \mathrm{a}$ 


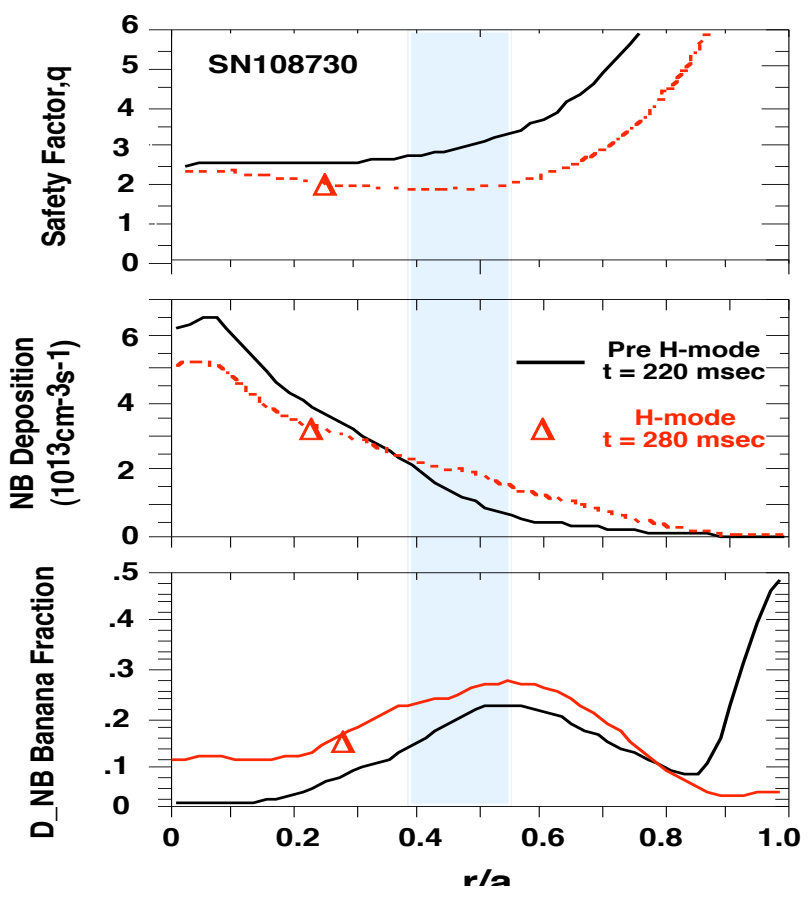

Figure 7. H-mode operation accelerates MHDinduced energetic ion loss.

$\sim 0.4$ - 0.5. Concurrently, the broad density profile shifts a significant fraction of core-weighted beam deposition to the same region, where the fraction of ions born on trapped banana orbits is higher. This behavior is typical for discharges like SN108730 in which an early $\mathrm{H}$-mode occurs shortly after turn on of the second neutral beam source. From this one may infer that MHD-induce ion loss is accelerated during $\mathrm{H}$-mode operation due to a congruous evolution of the q profile and beam deposition profile which feeds energetic trapped ions into the region of low-n MHD activity in the region r/a $~ 0.4-0.5$. Presumably the more energetic ions are the first to be lost because of their larger trapped orbits.

\section{Acknowledgement}

This work was supported by the United States Department of Energy under contract number DE-AC02-76CH03073.

[1] S. S. Medley, et al., Rev. Sci. Instrum. 69, 2651 (1998).

[2] W. W. Heidbrink, et al., Nucl. Fusion, In Press.

[3] S. S. Medley, et al., PPPL Report, PPPL-3668 (2002).

[4] E. D. Fredrickson, et al., Phys. Plasmas, In Press 


\section{External Distribution}

Plasma Research Laboratory, Australian National University, Australia

Professor I.R. Jones, Flinders University, Australia

Professor João Canalle, Instituto de Fisica DEQ/IF - UERJ, Brazil

Mr. Gerson O. Ludwig, Instituto Nacional de Pesquisas, Brazil

Dr. P.H. Sakanaka, Instituto Fisica, Brazil

The Librarian, Culham Laboratory, England

Mrs. S.A. Hutchinson, JET Library, England

Professor M.N. Bussac, Ecole Polytechnique, France

Librarian, Max-Planck-Institut für Plasmaphysik, Germany

Jolan Moldvai, Reports Library, Hungarian Academy of Sciences, Central Research Institute for Physics, Hungary

Dr. P. Kaw, Institute for Plasma Research, India

Ms. P.J. Pathak, Librarian, Institute for Plasma Research, India

Ms. Clelia De Palo, Associazione EURATOM-ENEA, Italy

Dr. G. Grosso, Instituto di Fisica del Plasma, Italy

Librarian, Naka Fusion Research Establishment, JAERI, Japan

Library, Laboratory for Complex Energy Processes, Institute for Advanced Study, Kyoto University, Japan

Research Information Center, National Institute for Fusion Science, Japan

Dr. O. Mitarai, Kyushu Tokai University, Japan

Dr. Jiangang Li, Institute of Plasma Physics, Chinese Academy of Sciences, People's Republic of China

Professor Yuping Huo, School of Physical Science and Technology, People's Republic of China

Library, Academia Sinica, Institute of Plasma Physics, People's Republic of China

Librarian, Institute of Physics, Chinese Academy of Sciences, People's Republic of China

Dr. S. Mirnov, TRINITI, Troitsk, Russian Federation, Russia

Dr. V.S. Strelkov, Kurchatov Institute, Russian Federation, Russia

Professor Peter Lukac, Katedra Fyziky Plazmy MFF UK, Mlynska dolina F-2, Komenskeho Univerzita, SK-842 15 Bratislava, Slovakia

Dr. G.S. Lee, Korea Basic Science Institute, South Korea

Institute for Plasma Research, University of Maryland, USA

Librarian, Fusion Energy Division, Oak Ridge National Laboratory, USA

Librarian, Institute of Fusion Studies, University of Texas, USA

Librarian, Magnetic Fusion Program, Lawrence Livermore National Laboratory, USA

Library, General Atomics, USA

Plasma Physics Group, Fusion Energy Research Program, University of California at San Diego, USA

Plasma Physics Library, Columbia University, USA

Alkesh Punjabi, Center for Fusion Research and Training, Hampton University, USA

Dr. W.M. Stacey, Fusion Research Center, Georgia Institute of Technology, USA

Dr. John Willis, U.S. Department of Energy, Office of Fusion Energy Sciences, USA

Mr. Paul H. Wright, Indianapolis, Indiana, USA 
The Princeton Plasma Physics Laboratory is operated by Princeton University under contract with the U.S. Department of Energy.

\author{
Information Services \\ Princeton Plasma Physics Laboratory \\ P.O. Box 451 \\ Princeton, NJ 08543
}

Phone: 609-243-2750

Fax: 609-243-2751

e-mail: pppl_info@pppl.gov

Internet Address: http://www.pppl.gov 